\title{
O ELO ENUNCIATIVO NA CANÇÃO POPULAR
}

\begin{abstract}
Álvaro Antônio Caretta*
Resumo: A partir do princípio dialógico da comunicação proposto pelo teórico russo Mikhail Bakhtin, desenvolvemos uma reflexão sobre o processo de enunciação. Tomando como objeto de estudo o gênero canção popular, observamos como o enunciado é o elo da cadeia de produção discursiva. Para isso, estudamos esse processo na canção "Dá nela", de Ary Barroso, enfocando a instauração do enunciador, a constituição de seu ethos e o estabelecimento das relações dialógicas com outros enunciados. Compreendendo a canção como um gênero discursivo secundário, originado pelo dialogismo entre a fala cotidiana, da esfera prosaica, $e$ a música, pertencente à esfera artística, tomamos as propostas de Tzevan Todorov sobre os processos de amplificação do ato de fala para observar como a canção se constitui dialogicamente no processo de produção discursiva.
\end{abstract}

Palavras-chave: dialogismo, canção popular, discurso, enunciação, Bakhtin.

\section{Introdução}

\begin{abstract}
A obra é um elo na cadeia de comunicação discursiva; como a réplica do diálogo, está vinculada a outras obras - enunciados: com aquelas às quais ela responde, e com aquelas que lhe respondem $[\ldots]$
\end{abstract}

(Bakhtin)

Todo enunciado pressupõe sua enunciação e, consequentemente, as posições enunciativas de enunciador e enunciatário. Vastamente estudada pelas teorias linguísticas, a enunciação é a célula da produção discursiva na comunicação social. Neste artigo, procuraremos demonstrar a constituição dialógica do processo enunciativo.

A princípio, pensamos a enunciação como um processo que ocorre em sucessão temporal, levantando as seguintes questões: o que ocorreu antes e o que ocorrerá depois da enunciação? Em se tratando dos processos de comunicação em uma comunidade discursiva,

Doutorando do Programa de Pós-Graduação em Semiótica e Linguística Geral do Departamento de Linguística da Faculdade de Letras da Universidade de São Paulo. 
podemos afirmar que houve e haverá outros processos enunciativos, já que entendemos o enunciado como um elo entre um enunciado anterior e um posterior.

Dessa forma, compreendemos a enunciação não apenas como ato de enunciar, mas como processo de transformação do enunciatário, que recebeu um enunciado, em enunciador, que produziu outro enunciado, alimentando a cadeia da produção discursiva. $\mathrm{O}$ enunciado é, então, o elo que liga os discursos, ou ainda, "nó em uma rede", como propôs Foucault (2004, p.26).

Entretanto, esse nó só é atado, e esse elo só é fechado, caso esse processo se repita ou até se perpetue. Do contrário, o enunciado perde-se no silêncio, como um segredo nunca revelado, ou melhor, sepultado.

\section{O dialogismo enunciativo na canção popular}

Inicialmente observemos esse processo enunciativo na réplica do diálogo cotidiano, tomando como exemplo este suposto diálogo:

\section{- Bom dia!!!}

- Só se for para você.

- Que péssimo humor, hein??!!

- Vê se me esquece!

Notamos que o processo de transformação do enunciador em enunciatário ocorre várias vezes. Ao dizer Bom dia, o enunciador inicia o diálogo; a resposta Só se for para você transforma o enunciatário em enunciador e assim consecutivamente.

Observando-se os três momentos desse processo enunciativo, o antes, o depois e a enunciação propriamente dita, pivô dessa transformação do enunciatário em enunciador, podemos perceber que, primeiramente, o enunciatário assimila o discurso de um enunciador, através de um enunciado, o que lhe possibilita, estimula, inspira e ou até obriga a produzir o seu próprio. Ao produzir um novo enunciado, ele assume a posição de enunciador, estabelecendo ao mesmo tempo um elo com os discursos anteriores e posteriores, elo que será fechado com a intercompreensão do enunciatário.

A réplica do diálogo, um gênero primário da esfera cotidiana, e a canção popular, um gênero secundário da esfera artística, possuem intensa relação dialógica.

Aqui é de especial importância atentar para a diferença essencial entre os gêneros discursivos primários (simples) e secundários (complexos) - não se trata de uma diferença funcional. Os gêneros discursivos secundários (complexos - romances, dramas, pesquisas científicas de toda espécie, os grandes gêneros publicísticos, etc.) surgem nas condições de um convívio cultural mais complexo e relativamente muito desenvolvido e organizado (predominantemente o escrito) - artístico, científico, sociopolítico, etc. No processo de sua formação eles incorporam e 
reelaboram diversos gêneros primários (simples), que se formaram nas condições da comunicação discursiva imediata (BAKHTIN, 2003, p.263).

Na canção popular o processo enunciativo é mais complexo do que na réplica do diálogo. Tomada como resposta a outros enunciados, a canção não é imediata. A enunciação da canção envolve diversas esferas discursivas, como a musical, a poética, a midiática, a cultural, etc.; no seu processo de produção e distribuição, a canção precisa ser composta, arranjada, tocada, gravada, cantada, vendida, comprada e ouvida. Esse processo exige tempo, porque nele estão envolvidas diversas esferas da comunicação social: a musical, a poético-literária, a fonográfica, a comercial, a jurídica etc.

\section{A amplificação da canção}

Na canção, o processo dialógico não se restringe à relação entre os enunciadores e os enunciatários, já que a enunciação possui uma complexidade que envolve diversas outras instâncias discursivas. Para aprofundarmos essa reflexão sobre o dialogismo do gênero canção, abordaremos as propostas de Todorov (1980, p. 46) sobre a origem dos gêneros:

A questão de origem que eu gostaria de formular, no entanto, não é de natureza histórica, mas sistemática; ambas parecem-me igualmente legítimas e necessárias. Não é: o que precedeu os gêneros no tempo? Mas: o que preside, a todo instante, o nascimento de um gênero? Mais exatamente, existiriam, na linguagem (pois que se trata aqui de gêneros do discurso), formas que, embora prenunciem o gênero, ainda não o são? E se houver, como se daria a passagem de uns aos outros? Mas, para tentar responder a essas questões, é preciso primeiro se perguntar: que é, no fundo, um gênero?

Ainda que Todorov esteja se referindo aos gêneros literários, a intenção de tratá-los como gêneros discursivos - declarada na passagem entre parênteses - permite-nos tomar suas considerações para estudar outros gêneros, como a canção popular. Inicialmente, é preciso ressaltar que, para o estudioso francês de origem búlgara ${ }^{1}$, o discurso é composto de enunciados, cujo processo de interpretação envolve tanto o elemento linguístico quanto o contexto de enunciação formado pelo locutor e pelo alocutário, num dado tempo, num dado lugar, em relação com um discurso precedente e subsequente. Todorov pressupõe que "[...] um discurso é sempre e necessariamente um ato de fala" (1985, p. 47).

$\mathrm{Na}$ comunicação social, determinadas recorrências discursivas são institucionalizadas, assim textos são produzidos e interpretados segundo normas estabelecidas pela prática discursiva de produção e codificação de enunciados. Todo gênero possui as suas propriedades discursivas que o singularizam frente a outros gêneros. Essas

\footnotetext{
$1 \quad$ Nascido em Sófia, na Bulgária, em 1939, Tzvetan Todorov mudou-se para Paris nos anos 60 e se
} nacionalizou francês. 
propriedades, observadas nos textos, dizem respeito ao seu aspecto semântico, sintático, pragmático e discursivo. Na concepção de Todorov (1985, p. 49), se a diferença entre um ato de fala e outro pode ser determinada por esses critérios, os gêneros, compreendidos como um ato de fala, também podem ser observados sob esses aspectos.

Partindo do pressuposto de que os gêneros se constituem a partir de atos de fala por meio de transformações chamadas "amplificações", Todorov (1980, p. 53) levanta a seguinte questão:

A nossa pergunta sobre a origem dos gêneros torna-se por conseguinte: quais as transformações que sofrem certos atos de fala para produzir certos gêneros literários?

O ato de fala é o núcleo dos gêneros discursivos. Ele é amplificado inicialmente por elementos retóricos como a narrativização, a expansão temática e a representação verbal. Todorov (1980, p. 58) propõe que o estudo dos gêneros literários - e discursivos - deve conceber a origem dos gêneros nos atos de fala e "[...] perceber que não existe abismo entre o que é literatura e o que não é literatura, que os gêneros literários têm por origem, simplesmente, o discurso humano".

Assim, um ato de fala sofre um processo de amplificações que o transforma em determinado gênero. No caso da canção popular, as amplificações são bastante diversas e complexas: a inicial seria a instauração de um enunciador-cancionista que transforma um ato de fala em um "ato de canto", ao elaborar um enunciado sincrético composto por elementos linguísticos relacionados a elementos musicais.

$\mathrm{O}$ cancionista mais parece um malabarista. Tem um controle de atividade que permite equilibrar a melodia no texto e o texto na melodia, distraidamente, como se para isso não despendesse qualquer esforço. Só habilidade, manha e improviso. Apenas malabarismo (TATIT, 1996, p.9).

A amplificação, tomada em seu aspecto literal, é o processo de tornar mais amplo o campo que determinado objeto ocupa. No caso de uma canção, o seu ato de fala original, tem que ultrapassar a relação entre um destinador e um destinatário e alcançar vários destinatários, entendidos como um grupo social. Essa amplificação só é possível por meio da mídia, elemento fundamental na constituição do gênero canção popular. Por meio do disco e do rádio nas primeiras décadas do século XX, a canção se constituiu como um dos principais gêneros da sociedade brasileira.

Ainda que, em seu processo de amplificação, uma canção vise a um grupo social ouvinte e consumidor, o seu enunciado não pode prescindir da relação entre um destinador e um destinatário que remeta a um ato de fala original.

Com inflexões similares às da linguagem oral cotidiana, essas melodias geralmente conduziam "letras de situação", aquelas que simulam que alguém está falando com 
alguém em tom de recado, desafio, saudação, ironia, lamentação, revelação etc. (TATIT, 2004, p.77).

\section{O ethos do enunciador}

Um dos aspectos mais importantes do processo de amplificação do ato de fala na canção é a instauração do enunciador. A Análise do Discurso compreende o enunciado como produto de uma enunciação, por exemplo, um ato de fala, um texto escrito, cantado etc., e toda enunciação pressupõe um enunciador.

De acordo com (Charaudeau; Maingueneau, 2004, p.220):

O enunciador deve legitimar seu dizer: em seu discurso, ele se atribui uma posição institucional e marca sua relação a um saber. No entanto, ele não se manifesta somente como um papel e um estatuto, ele se deixa apreender também como uma voz e um corpo. O ethos se traduz também no tom, que se relaciona tanto ao escrito quanto ao falado, e que se apóia em uma "dupla figura do enunciador, aquela de um caráter e de uma corporalidade".

O ethos é, então, constituído por um caráter, conjunto de características psicológicas e ideológicas, e por uma corporalidade, determinada pelo modo como o enunciador ocupa um espaço social. Essa constituição está relacionada ao papel que o enunciador pretende representar frente ao enunciatário.

Compreendido como um efeito de sentido do discurso, o ethos pode ser estudado no estilo do enunciador, a sua "maneira de dizer" que configura a sua "maneira de ser". Particularmente na canção, essa "maneira de dizer" é uma "maneira de compor", estabelecida pelo modo como o enunciador relaciona os componentes linguístico e musical.

O enunciador não só representa o seu papel como também constrói uma cena, um "palco enunciativo". Maingueneau (2001a, p.86) propõe três cenas da enunciação: a cena englobante, a cena genérica e a cenografia.

A cena englobante é o tipo de discurso a que determinado enunciado está vinculado. Por exemplo, a cena englobante de um poema é literária; de uma oração, religiosa; no caso da canção, a cena englobante pode ser compreendida como artístico-musical. Por ser a canção um gênero do discurso artístico, o enunciador explora os recursos estilísticos da língua e da música.

A cena genérica é determina pelo gênero discursivo ao qual o enunciado está vinculado. Maingueneau (2001a, p.86) assevera:

Dizer que a cena de enunciação de um enunciado político é a cena englobante política, ou que a cena de um enunciado filosófico é a cena englobante filosófica etc. é insuficiente: um co-enunciador não está tratando com o político ou com o filosófico em geral, mas sim com gêneros de discurso particulares. Cada gênero de discurso define seus próprios papéis: num panfleto de campanha eleitoral, trata-se 
de um "candidato" dirigindo-se a "eleitores"; numa aula, trata-se de um professor dirigindo-se a alunos etc.

No caso de uma canção, um enunciador assume o papel de cancionista, cantando para um enunciatário, o ouvinte. Este espera um enunciado musical, cantado, com uma letra que lhe provoque um sentimento, uma reflexão, um estímulo corporal - como na dança - ou simplesmente um momento de lazer. sua fala.

A cenografia é a situação de enunciação que o enunciador cria a fim de legitimar a

A cenografia é, assim, ao mesmo tempo, aquilo de onde vem o discurso e aquilo que esse discurso engendra; ela legitima um enunciado que, em troca deve legitimá-la, deve estabelecer que essa cenografia da qual vem a fala é, precisamente, $a$ cenografia necessária para contar uma história, denunciar uma injustiça, apresentar sua candidatura a uma eleição etc. (CHARAUDEAU; MAINGUENEAU, 2004, p. 96).

Para Maingueneau (2001, p. 138), o ethos é "a dimensão da cenografia em que a voz do enunciador se associa a uma certa dimensão do corpo". Essa voz é responsável por exprimir a interioridade do enunciador e envolver o enunciatário. O ethos não é o próprio enunciador, mas uma imagem em que ele investe para representá-lo, consoante suas intenções discursivas.

Por se tratar de uma dimensão da cenografia, o ethos se estabelece de acordo com as propriedades discursivas que a constituem.

\begin{abstract}
A cenografia implica, desse modo, um processo de enlaçamento paradoxal. Logo de início, a fala supõe uma certa situação de enunciação que, na realidade, vai sendo validada progressivamente por intermédio da própria enunciação. Desse modo, a cenografia é ao mesmo tempo a fonte do discurso e aquilo que ele engendra; ela legitima um enunciado que, por sua vez, deve legitimá-la, estabelecendo que essa cenografia onde nasce a fala é precisamente a cenografia exigida para enunciar como convém, segundo o caso, a política, a filosofia, a ciência, ou para promover certa mercadoria [...](MAINGUENEAU, 2004, p.96).
\end{abstract}

Da mesma forma que a cenografia, o ethos se configura segundo esse paradoxo constitutivo. À proporção que a imagem do enunciador ganha corpo através da enunciação, ela própria se estabelece por meio desse ethos, visto que a enunciação efetiva-se através do código lingüístico e musical, no caso da canção, que só se torna eficiente se associado a uma imagem que lhe corresponda.

A constituição do ethos por meio da linguagem é um processo que abarca a própria corporalidade textual determinada em função dos gêneros discursivos. 


\begin{abstract}
A "incorporação" que o etos convoca desenvolve-se ela própria a partir de uma corporalidade tão evidente que nos arriscamos a esquecê-la: a do texto. A obra não é apenas um certo modo de enunciação, constitui também uma totalidade material que, enquanto tal, é objeto de um investimento pelo imaginário. Em particular, qualquer obra tem um tamanho determinado e implica uma divisão específica (em partes, capítulos, estrofes...), não independente da cenografia e do conteúdo das obras (MAINGUENEAU, 2001 p.151).
\end{abstract}

Com base nessas propostas, procuramos avançar pelo estudo da relação entre ethos e gênero discursivo. Como afirma Discini (2003, p. 57), "Estilo é ethos, é modo de dizer, implicando esse ethos um policiamento tácito do corpo, uma maneira de habilitar o espaço social $[. .] "$, logo podemos considerar que o estilo do enunciador-cancionista configura a sua imagem frente ao enunciatário-ouvinte.

O gênero exige do enunciador um estilo que corresponderá a um determinado ethos. Por exemplo, no gênero aula, deve predominar um estilo claro, bem organizado, exemplificativo etc.; caraterísticas que determinam uma ethos didático. Como esse gênero possibilita ao enunciador uma liberdade na escolha de seu "modo de dizer", ou seja, ele pode optar por um ou outro estilo, uma ou outra cenografia para realizar a sua enunciação, ele pode assumir ethé diversos, como intolerante, compreensivo, humorístico, disciplinador etc.

Seguindo esse raciocínio, ao ethos exigido pela cena genérica nós chamaremos "inerente"; àquele pelo qual o enunciador pode optar, "assumido". A fim de constituir o seu ethos inerente, o enunciador orienta-se pelas regras impostas pelo gênero no que diz respeito à constituição textual e ao estilo. Entretando, em gêneros que permitem uma liberdade de estilos, o enunciador pode assumir ethé diversos.

A cenografia nas canções é constituída por um gênero da fala. Esse aspecto faz esse gênero apresentar duas instâncias enunciativas. A primeira, determinada pela cena genérica, é estabelecida pela relação entre um enunciador que canta um enunciado para um enunciatário. A segunda, presente na cenografia da letra, ocorre entre um destinador que fala algo para um destinatário. Esse processo de análise que executamos ao distinguir essas duas instâncias tem como finalidade demonstrar que o ethos do enunciador na canção é consequência da interação entre o gênero e a cenografia.

Os conceitos de ethos inerente e ethos assumido são pertinentes para compreendermos a formação da imagem do enunciador na canção, visto que nos permitem discernir a constituição do ethos na cena genérica e na cenografia. Designamos ethos inerente a imagem que o enunciador cria de si para o enunciatário, tendo em vista as exigências do gênero. A canção, por pertencer à esfera artística, exige que o enunciador apresente um ethos inerente musical, criativo e poético para que possa validar a sua enunciação frente ao enunciatário-ouvinte.

$\mathrm{O}$ ethos assumido, que pertence à cenografia, é a imagem que o destinador cria para si frente ao destinatário na situação de fala encenada. Como a canção é um gênero que permite a liberdade de escolha da cenografia, o enunciador pode criar inúmeras outras imagens para si no discurso. Ele pode, por exemplo, apresentar-se apaixonado como em "Carinhoso", de Pixinguinha e João de Barro; pode ser suplicante e desesperado, como em "Volta", de Lupicínio Rodrigues; ou pode ser também sutilmente malicioso, como na marcha "O teu cabelo não nega", de Lamartine Babo e irmãos Valença. 
Apesar de distinguirmos esses dois ethé, inerente e assumido, respectivamente na cena genérica e na cenografia, é importante não perder de vista que ambos concorrem para a constituição do ethos do enunciador. A fala é responsável pela gestualidade oral que corporifica o enunciador-cancionista, constituindo o corpo vivo, humano, real. Ela emana da cenografia através de um gênero prosaico que pode ser uma declaração, um lamento, um pedido etc. A melodia vai além do corpo físico e produz o efeito estético. É por meio dela que o ato de fala, um gênero prosaico, torna-se canto e transforma-se em um gênero artístico, a canção.

\section{Estudo de caso}

A partir dessas propostas, observaremos como ocorre o processo dialógico da enunciação no gênero canção popular, tomando como exemplo a marchinha carnavalesca Dá Nela, de Ary Barroso.

"Dá Nela"²

Essa mulher há muito tempo me provoca

Dá nela, Dá nela

É perigosa, fala que nem pata choca

Dá nela, Dá nela.

Fala, língua de trapo

Pois da tua boca eu não escapo

Agora deu para falar abertamente

Dá nela, Dá nela

É intrigante, tem veneno e mata a gente

Dá nela, Dá nela

Vencedora do primeiro concurso de música carnavalesca organizado pela Casa Edison em 18 de janeiro de 1930, essa marchinha, do então emergente compositor Ary Barroso, gravada por Francisco Alves, foi a mais cantada pelos foliões no carnaval daquele ano.

Um incidente de rua em que populares gritavam "dá nela", ameaçando bater em uma mulher, acabou fornecendo o mote para Ari Barroso escrever esta marchinha, vencedora do concurso de músicas para o carnaval de 30. Embora longe de ser um primor de composição - foi escrita às pressas, no dia do concurso -, "Dá nela" caiu logo no gosto do povo, sendo aproveitada num espetáculo de revista a que deu o nome. Mas, como sempre acontece em composições musicais, houve quem não

2 Essa canção pode ser ouvida no site www.geocities.com/aochiadobrasileiro/. 
gostasse de sua vitória, no caso o polêmico Sinhô que, com o pseudônimo de Zé Baião, replicou com o samba "Dá nele" [...] (SEVERIANO E MELLO, 1998, p.99).

Tomando a canção "Dá nela" como um enunciado na cadeia discursiva, procuraremos compreender como ela se constitui dialogicamente em relação aos enunciados anteriores que contribuíram com a sua realização e aos posteriores que ela propiciou. Nessa tarefa, poderemos observar o processo dialógico de estabelecimento do enunciador.

O episódio relatado acima exemplifica como o enunciado, no caso a marchinha "Dá nela", é um elo da cadeia, ou um nó da teia discursiva. Após ouvir a expressão "dá nela", proferida por um grupo de populares, Ary Barroso compôs essa marchinha que foi cantada por muitos foliões. Dessa forma, o compositor mineiro passou da categoria de enunciatário para enunciador, ao tomar essa expressão pertencente à esfera prosaica do cotidiano e amplificá-la através de uma enunciação musical.

O fato de o polêmico sambista Sinhô partir dessa canção para compor "Dá nele", não só repete o processo enunciativo de transformação do enunciatário em enunciador, como dá continuidade ao processo dialógico de instituição das comunidades discursivas, agregando compositores, intérpretes, músicos, ouvintes, rádios, gravadoras, todos aqueles potencialmente constituídos para enunciar nessa prática discursiva, a canção popular.

Em sua composição, Sinhô, dirige-se diretamente ao enunciador de "Dá Nela". Essa resposta estabelece o elo discursivo em um exercício de intertextualidade, como podemos observar:

"Dá Nele" 3

Não tens razão

Pra falar mal da mulher

Dá nele! Dá nele!

Isto é paixão

Porque ela não te quer

Dá nele! Dá nele!

Ela não teme

Que chames língua de trapo

Pois que o povo bem conhece

As maldades do farrapo

Por isso mesmo

Muito tens que apanhar

Nas vistas de toda gente

Pra língua endireitar

3 Essa canção pode ser ouvida no CD Sinhô. Alivia teus olhos: volume 2. Curitiba: Revivendo. 
A partir dos títulos já se nota que o enunciador de "Dá nele" estabelece um diálogo com o enunciador de "Dá nela". A intertextualidade pode ser observada nas passagens Não tens razão/ Pra falar mal da mulher, dirigindo-se a um enunciatário, que fora enunciador na canção "Dá nela", e no refrão Dá nele, que subverte Dá nela.

Ainda que melodicamente diferentes, ambos os refrões são interpretados por um conjunto vocal, diferenciando-os, assim, da fala do enunciador. Esse arranjo remete à cenografia presente na letra. "Dá nela" apresenta um destinador falando com um destinatário a respeito de uma mulher e, a seguir, uma resposta, que soa como uma sentença, do grupo de populares. Essa resposta exerce a função de refrão, cantado pelos acompanhantes, que representam os populares.

A intertextualidade é evidente na segunda parte de "Dá nele", em que aparece a expressão língua de trapo no final do verso, como ocorre em "Dá nela". Além disso, o verso seguinte de ambas as composições inicia-se pela conjunção explicativa pois e termina com uma rima em apo:

\section{Fala, língua de trapo}

Pois da tua língua eu não escapo

Ela não teme

Que chames língua de trapo

Pois que o povo conhece

As maldades do farrapo

Na última parte do samba "Dá nele", temos a conclusão do enunciador com relação a essa polêmica. Ele afirma que o enunciador de "Dá nela" merece apanhar devido a sua língua ferina, ou seja, o mesmo argumento utilizado por este para justificar a agressão à mulher.

$\mathrm{Na}$ canção, o ethos do enunciador deve ser pensado tendo em vista fundamentalmente duas instâncias: o gênero e a cenografia. A instância genérica determina o ethos inerente, e a cenografia, o ethos assumido. Entretanto, é preciso levar em conta também o estilo musical da canção.

A marchinha é uma "Modalidade de fundo brejeiro, fácil de reter e dançar, e ademais se prestando à crítica, à sátira, à galhofa [...]" (Alencar, 1979, p.46). Esses elementos encontramos em "Dá nela", constituindo o ethos inerente. Com relação ao ethos assumido, ou seja, aquele que o enunciador assume para si na cenografia, o enunciador de "Dá nela" mostra-se perseguido (Essa mulher há muito tempo me provoca) e agressivo (Fala, língua de trapo, Dá nela). Essa intolerância agressiva que caracteriza o enunciador é enfatizada pelo fato de a expressão Dá nela ser repetida como um refrão. No entanto, como aparece em uma marchinha, esse ethos é suavizado e apreendido de forma satírica.

Já no samba "Dá nele", que não foi composto para o carnaval, o enunciador apresenta um ethos assumido crítico (Não tens razão/Pra falar mal da mulher) e agressivo (Muito tens que apanhar, Dá nele). Esse ethos constitui-se em função do enunciador de "Dá nela", visto que as duas canções estão em relação polêmica, deixando evidente o dialogismo discursivo. 


\section{Conclusão}

Se o enunciado é um elo da cadeia discursiva, como propôs Bakhtin, para estudá-lo é preciso observar as relações que ele estabelece com outros enunciados. No caso que investigamos, a canção "Dá nela" estabelece-se dialogicamente através de um processo de amplificação. A partir de um gênero primário - a réplica do diálogo - o enunciado se constrói por meio da instauração de um enunciador, que valida inicialmente o seu ethos inerente de cancionista, ao relacionar a fala com a música. Esse enunciador constrói uma cenografia na qual remete a uma situação de fala cotidiana, constituindo assim o seu ethos assumido como intolerante.

A fim de evidenciar o processo dialógico de produção do enunciado, demonstramos a intertextualidade existente entre essa marcha e o samba "Dá nele", cujo enunciador constitui-se por meio de uma relação polêmica. Dessa forma, pudemos observar que não apenas o enunciado, mas todos os aspectos relacionados à produção discursiva - a esfera, $o$ gênero e a própria enunciação - constituem-se dialogicamente.

\section{Referências bibliográficas}

ALENCAR, Edigar de. O carnaval carioca através da música. Rio de janeiro: Livraria Francisco Alves Editora, 1979.

BAKHTIN, Mikhail. Estética da criação verbal. São Paulo: Martins Fontes, 2003.

CHARAUDEAU, Patrick e MAINGUENEAU, Dominique. Dicionário de análise do discurso. São Paulo: Contexto, 2004.

DISCINI, Norma. O estilo nos textos. São Paulo: Contexto, 2003.

FOUCAULT, Michel. A arqueologia do saber. Rio de Janeiro: Forense Universitária, 2004.

MAINGUENEAU, Dominique. O contexto da obra literária: Enunciação, escritor, sociedade. São Paulo: Martins Fontes, 2001.

Análise de textos de comunicação. São Paulo: Cortez Editora, 2001a.

SEVERIANO, Jairo e MELLO, Zuza Homem de. A canção no tempo: 85 anos de músicas brasileiras (Vol. 1). São Paulo: Editora 34, 1997.

TATIT, Luiz. O Cancionista. São Paulo: Editora da Universidade de São Paulo, 1996.

O Século da canção. Cotia: Ateliê Editorial, 2004.

TODOROV, Tzvetan. Os gêneros do discurso. São Paulo: Martins Fontes, 1980

Abstract: From the dialogic principle of the communication considered for Mikhail Bakhtin, we develop a reflection on the enunciation process. Taking as study object the sort popular song, we observe as the utterance is the link of the chain of discoursive production. For this, we study this process in the song "Dá nela", of Ary Barroso, focusing the instauration of the enunciator, the constitution of its ethos and the establishment of the dialogics relations with other utterances. 
Understanding the song as a secondary discursiv sort, originated for the dialogism between it speaks daily, of the prosaic sphere, and music, pertaining to the artistic sphere, we take the proposals of Tzevan Todorov on the processes of amplification of the act of speaks to observe as the song if it constitutes dialogicamente in the process of discoursive production.

Key-words: dialogism, popular song, discourse, enunciation, Bakhtin. 